\title{
4
}

\section{The object-oriented modeling for product data management (PDM)}

\author{
Sunn-Ho Kim • Tae-Hoon Oh \\ Department of Industrial Engineering \\ Myong-Ji University \\ San38-2, Nam-dong, Yongin-si, Kyunggi-do 449-728, Korea \\ Phone: +82-335-30-6451 FAX: +82-335-35-9998 \\ Email: shk@wh.myongji.ac.kr
}

Joo-Young Park

Hyundai Information Technology Co., Ltd.

12Fl. Woorim Bldg., 136-6 Seocho-dong

Seocho-gu, Seoul 137-070, Korea

\begin{abstract}
Current commercialized PDM tools have drawbacks in representing a variety of data types such as CAD data, images, audio, long text, etc. by relational data modeling. For this reason, object-oriented approaches have been suggested as an alternative. In this paper, using the object-oriented paradigm, an object-oriented data model for the PDM system is proposed. The scope of the modeling is limited to management information for drawings, parts, and product structure. Rumbaugh's OMT (Object Modeling Technique) has been adopted for the system design. In the modeling, classes of data vault and workspace are taken into account for the review or approval of drawings and parts data based on the concurrent engineering concept. For parts and corresponding product structure, classes of phantoms, options, substitutes, etc. are added to the model. In addition, state transition and data flow diagrams are suggested based on the analysis of work and data flows of drawings and parts.
\end{abstract}

\section{Keywords}

PDM, object-oriented modeling, OMT, concurrent engineering, 


\section{INTRODUCTION}

In recent years, the interest of industry begins to change from cost reduction and quality improvement to reduction of the time-to-market of new products. In other words, in order for the industry to strengthen a competitive position in markets and pursue a continuous improvement, new strategies are required so that the industry can respond quickly to customer's needs placing emphasis on diversification, high quality, and differentiation of products (Kim, 1994).

As one of the strategies, a Concurrent Engineering (CE) concept has been applied to product design processes. $\mathrm{CE}$ takes into account most of engineering and manufacturing information related throughout a product's life cycle period, based on harmonious communications among product development teams, sharing of information, and simultaneous processes.

PDM (Product Data Management) is one of the systematic approaches for the implementation of CE. PDM makes concurrent processes possible by managing comprehensively design and drawing tools, engineering data bases, shared electronic documents, etc. In other words, it provides users with all the information needed at desired places in adequate formats at an appropriate point of time (HP1993, CIMdata 1994, Lee 1996, Choi 1995).

In general, PDM deals with data such as drawings, documents, product structure, engineering data, workflow and processes, project management, etc. concerned with product development. However, as this data consists of complex structured data, image or vectored files, voice, audio, etc., it is not convenient to treat the data with current PDM tools oriented to relational databases.

Relational DBMSs have been developed to fit applications which need static or simple data used in business areas with data represented in a table format. For this reason, traditional RDBMSs have a drawback for not adequately serving certain applications. These include CAD/CAM, CASE, multimedia, and systems with very complex objects (Samsung HP 1993, Lee 1996, Kim 1994, Shin 1995, Kim 1994). There has been continual effort in developing PDM systems for several years. However, the PDM systems have the same problems of RDBMS.

To overcome this problem, researchers (Kim 1992, Chung 1994) proposed a data modeling based on an object-oriented approach. Even in STEP (STandard for the Exchange of Product model data), data models are represented by the objectoriented modeling language, EXPRESS (Yoo, 1995). With ODBMSs, it is easy to treat long transactions in $\mathrm{CAD}$, versioning, unstructured objects, and complex objects (McHenry, 1993). In addition, it is possible to represent semantic concepts such as generalization and aggregation and to handle engineering data which has a hierarchical structure of composite objects (Chung, 1994).

For these reasons, in this research we analyze product data from the viewpoint of "objects" and propose a data model for PDM systems using an object-oriented paradigm. In the model, classes of workspaces and vaults are taken into account for concurrent information sharing of documents such as drawings, parts. etc. In the 
modeling of product structures, the concepts of phantom (or virtual) parts, optional parts, and substitutes are included. In addition, based on the analysis of the processes and data flows, state transition and data flow diagrams for drawings and parts are also proposed. As a modeling methodology, Rumbaugh's OMT (Object Modeling Technique) is used (Rumbaugh,1991).

\section{CONCURRENT ENGINEERING IN PDM}

For simultaneous processes of data, reviewer's opinions must be gathered concurrently through the network. Figure 1 shows this concept (CIMLINK, 1991). A document is generated by the integration of drawings and parts data and this is sent in parallel to all members of a designated group simultaneously for the review or approval. They attach their comments to the drawings by redlining and markup or by electronic mail through terminals. Reviewer's annotations are collected and combined with the original document for consideration by its creator. Through this process of review, annotation and feedback, CE-based engineering changes, approvals and notifications are carried out (Kim, 1996).

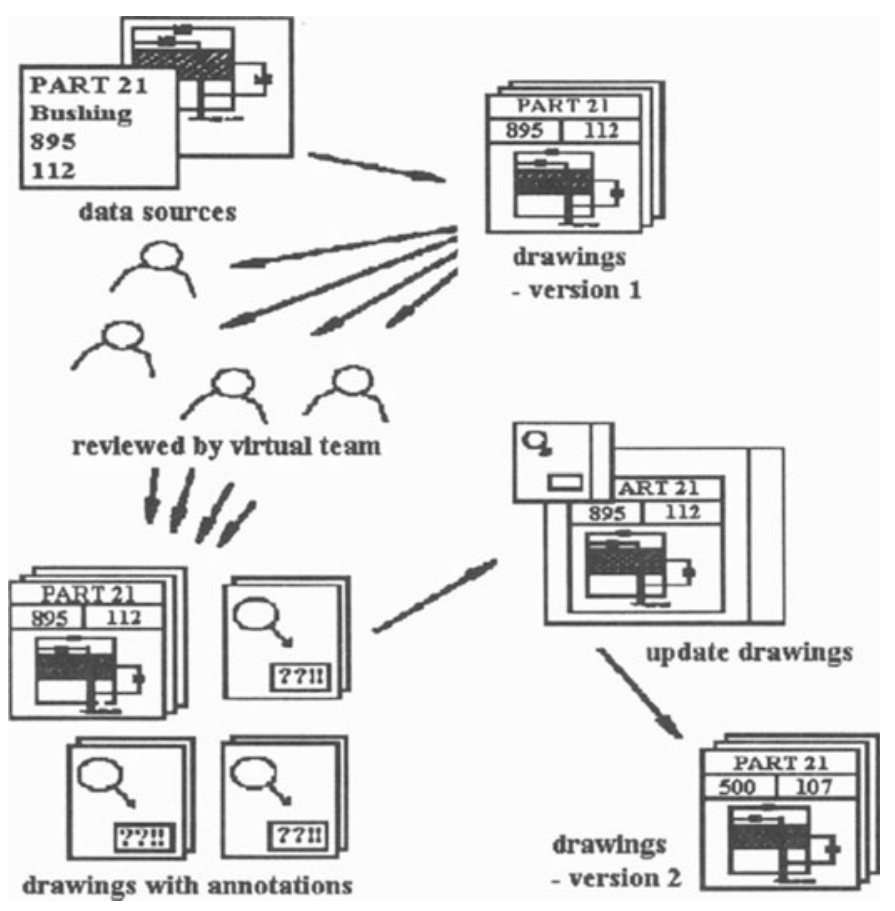

Figure 1. The concurrent engineering control for drawings (CIMLINK, 1991) 
As shown in Figure 2, all data concerned with product development is managed through the processes of generation, change, release, and disposal based on the CE concept, and stored in an electronic vault or workspaces. In the workspaces, the data under progress by designers or other users is stored. In case the needs for data share occur after the completion of these processes, the data moves to the vault by a scenario of workflow (Lee, 1996).

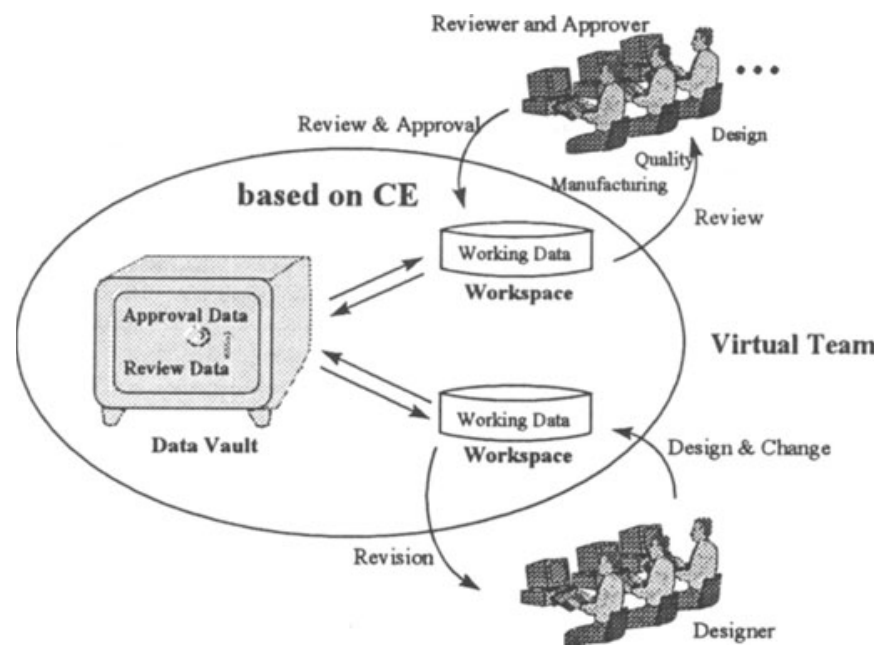

Figure 2. Data flow based on CE.

\section{OBJECT-ORIENTED MODELING FOR PDM}

\subsection{Introduction}

Most of the object-oriented methods are based on object-oriented paradigms and approach world models from two related viewpoints: the static relation and the dynamic behavior. In Rumbaugh's object-modeling technique (OMT), three views of modeling systems are used: 1) object modeling, 2) dynamic modeling, and 3) functional modeling (Choi 1996, Rumbaugh 1991).

The object modeling represents the structure of objects or classes in a system their identity, their relationships to other objects, their attributes, and their operations. These remain unchanged regardless of the time flow or sequencing of operations. Associations, generalization and inheritances, aggregations, etc. are included in the static relation. An association is a special case of inheritances and aggregations and describes a group of links with common structure and common semantics. In addition, although they are modeled as bi-directional they do not have to be implemented in both directions. They can be implemented as pointers if it is only traversed in a single direction. Generalization and inheritance are 
powerful abstractions for sharing similarities among classes while preserving their differences. Inheritance means that a subclass inherits attributes and methods from one or more superclasses. In this concept, the subclass can have its own attributes and methods regardless of attributes and methods of its superclasses. Aggregation is the "part-whole" or "a-part-of" relationship in which objects representing the components of something are associated with an object representing the entire assembly (Taylor, 1990).

Dynamic modeling describes that aspect of a system concerned with time and the sequencing of operations - events that mark changes, sequences of events, states that define the context for events, and the organization of events and states. This model is represented graphically with state diagrams. Each state diagram shows the state and event sequence permitted in a system for one class of objects.

The functional modeling describes those aspects of a system concerned with transformations of values-functions, mappings, constraints, and functional dependencies. The functional model captures what a system does without regard for how or when it is done. It is represented with data flow diagrams. Data flow diagrams show the dependencies between values and the computation of output values from input values and functions, without regard for when or if the functions are executed (Rumbaugh 1991, Choi 1995).

\subsection{Identification of Object Classes and Object Modeling}

For the constnuction of object models for PDM, objects and their classes have to be identified in advance and their relations defined such as associations, generalization and inheritance, aggregations, etc. In this stage, attributes and methods, which describe characteristics of the classes, may be included in static diagrams. The PDM system proposed in this research consists of three modules, i.e., drawing data management, part data management, and product structure management modules. Object classes identified for these modules are summarized in Table 1. The association diagram among the classes is shown in Figure 3.

Table 1. Objects identified in PDM

\begin{tabular}{|l|l|}
\hline Module & Objects \\
\hline $\begin{array}{l}\text { drawing data } \\
\text { management }\end{array}$ & $\begin{array}{l}\text { drawing, drawing history, edition history, check history, } \\
\text { approval history, disposal history, release history, version }\end{array}$ \\
\hline $\begin{array}{l}\text { part data } \\
\text { management }\end{array}$ & $\begin{array}{l}\text { part, part information, GT-code, supplier, alternate, product, } \\
\text { assembly, component }\end{array}$ \\
\hline $\begin{array}{l}\text { product structure } \\
\text { management }\end{array}$ & $\begin{array}{l}\text { product, BOM information, family information, phantom, } \\
\text { common module, option module, kit }\end{array}$ \\
\hline $\begin{array}{l}\text { data share } \\
\text { management }\end{array}$ & $\begin{array}{l}\text { vault, vault location, workspace, work location, user, user's } \\
\text { role, authority }\end{array}$ \\
\hline
\end{tabular}




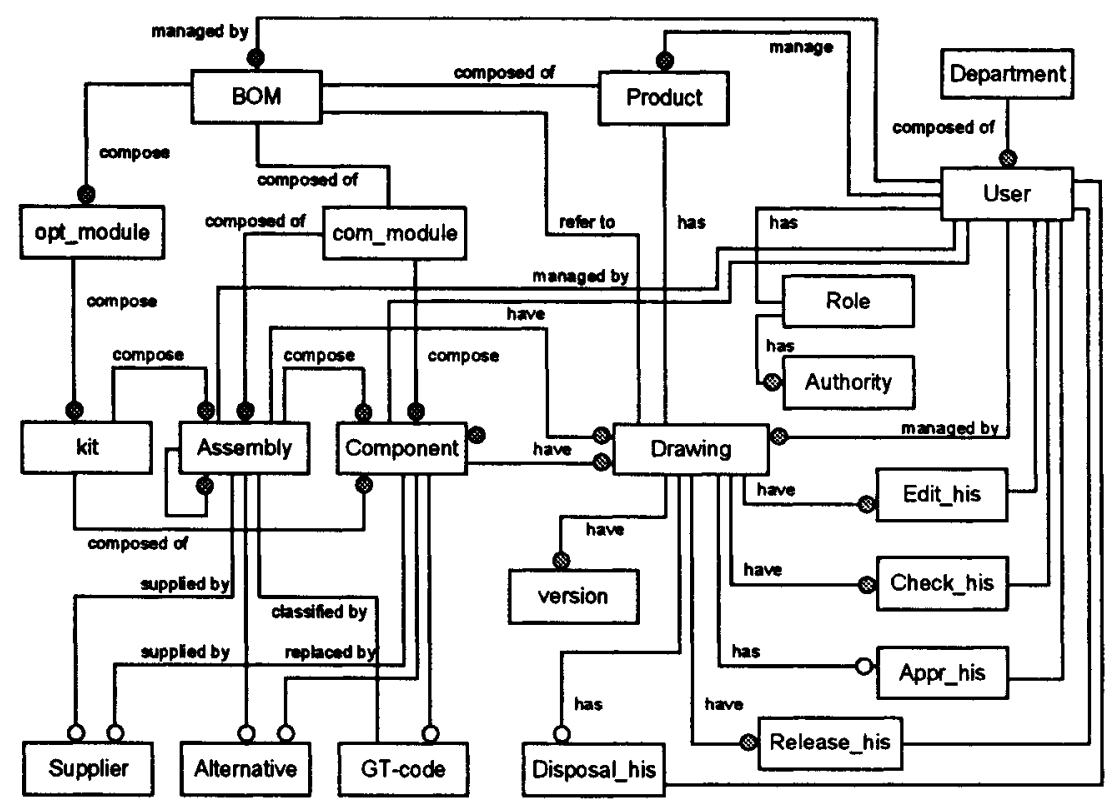

Figure 3. A class association diagram

\subsection{Object Modeling for Drawing Data Management}

Documents concerned with a product design include drawings, specifications, instructions, standards, 3D models, technical documents, etc. Each document can have common attributes of document number, author, written date, etc. Figure 4 represents the relations of generalization and inheritance by generating a superclass named "document" and inheriting its attributes to subclasses named "Drawing", "Standard", "Instruction", and "Spec.". A new document class can be created by inheritance of attributes of its abstract class and addition of its own attributes. Figure 4 also shows the object model of the drawing data management module. A drawing generates history data of edition, check, approval, release, disposal, version, etc. through the workflow and life cycle period of time. These history classes create an abstract class of "Drawing_his" and keep the relation of generalization. On the other hand, the drawing history class becomes a composite object of the drawing class, "Drawing", and history classes under the drawing history class become component objects. This represents an aggregation which have the relation of "a_part_of". When such document objects related to a drawing are treated as composite objects, corresponding data can be kept consistently by class dependency. 


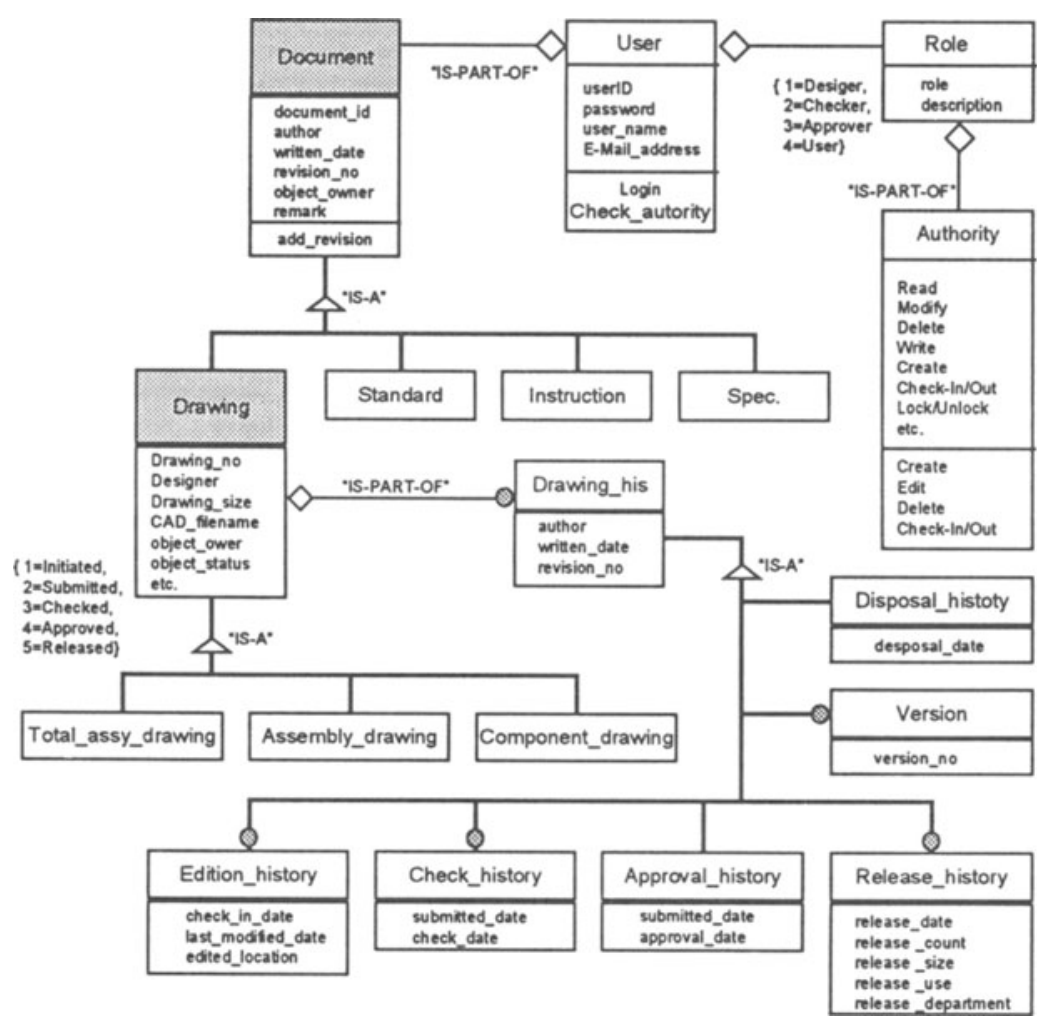

Figure 4. The object model for drawing data management

\subsection{Object Modeling for Part Data Management}

An object model for the part data management is shown in Figure 5. In the figure, classes "Assembly" and "Component" have common attributes of part number, part name, parent part number, GT code, etc., and common methods of creation, revision, query, deletion, print, etc. These two classes can be generalized by creating an abstract class named "Part". In this object model, "Component" implies objects which consist of raw materials and unit parts and "Assembly" objects which consist of component parts and subassemblies. The class "Alternate" means alternate parts replaced when standard parts can not be used and have attributes of effective date and effective quantity for alternate control. In addition, classes of "Supplier", "Alternate", "GT-code", and "Drawing" are dependent on the part information class "Part_Info" and construct a relation of aggregation. Here, "PartInfo" becomes a dependent object of the class "Part". 


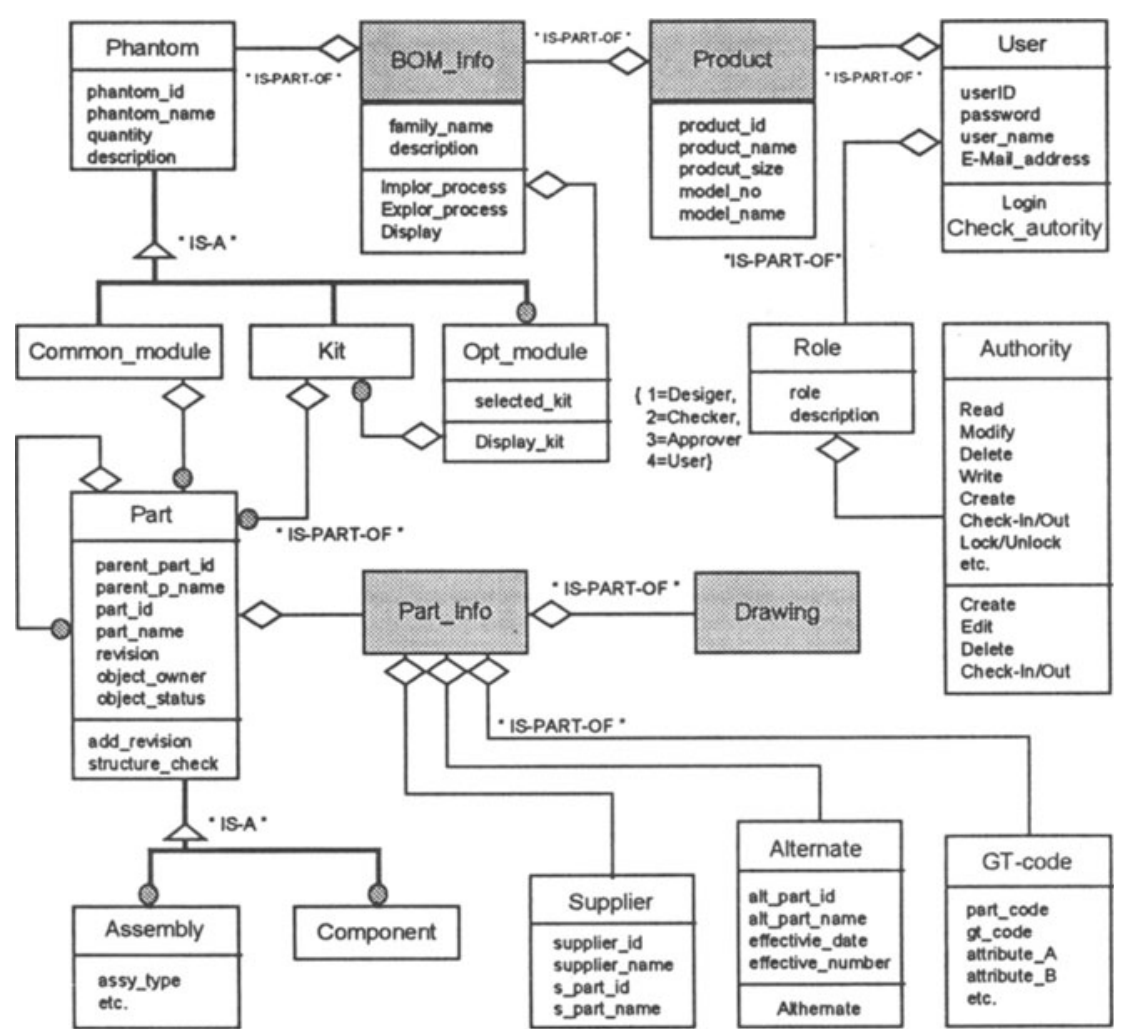

Figure 5. The object model for part data management

\subsection{Object Modeling for BOM}

Under the environment where a variety of options for a product exists, BOM data must be managed in terms of options. For this reason, in this research, the product structure is modeled based on the concept of family BOM. Family BOM is a data structure where products of similar characteristics are grouped into family and the product structures of the family are represented by modularized common and optional parts. In this method, common and optional parts have their own product structures and a BOM is generated by the selection of the common and optional parts.

In the object model proposed in Figure 5, a BOM is created with classes of "Common_module", "Option_module", and "Kit". Above these three classes is the superclass "Phantom" which means a virtual part. Virtual parts are not included in the parts list for manufacturing or assembly, but used as group names of common, 
optional, and kit parts for the convenience of design or planning. Common modules, the one which classify parts commonly used in a product group, consist of assembly parts and component parts. Kits, i.e., virtual parts which represent optional specifications, also consist of assembly parts and component parts. Optional modules are the kits classified by grouping optional specifications within a product group.

\subsection{Object Modeling for Data Share}

As shown in Figures 2 and 6, in order for users to create, change, review, and approve objects concerned with a product such as drawings, parts, documents, etc., these objects have to be transferred from workspaces where data is not shared to vaults where data is shared. This function is called "check-in" and reverse the function, which gets data from the vaults is called "check-out". Document information consists of meta data which includes location or index data, and corresponding documents such as CAD files, image files, text files, audio data, video data, etc. These two types of data must be stored separately in vaults or workspaces. Figure 7 represents the object model for the whole system including the object model for data share.

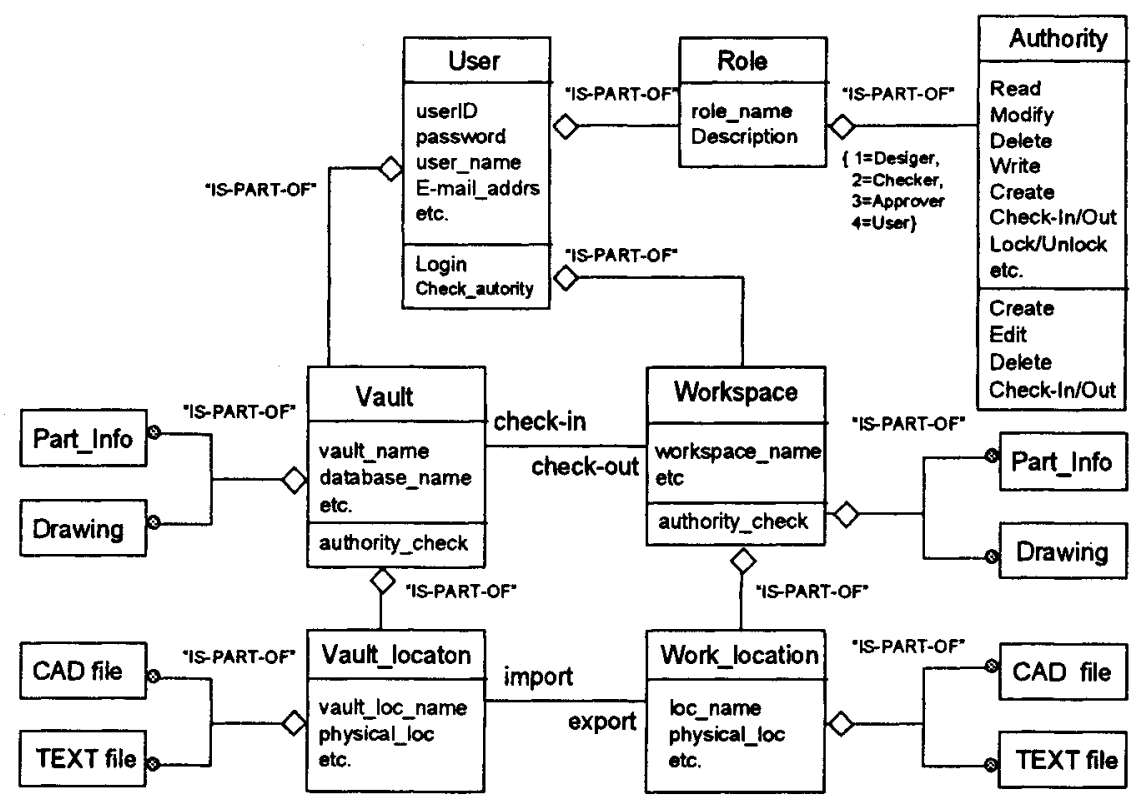

Figure 6. The object model for data share 


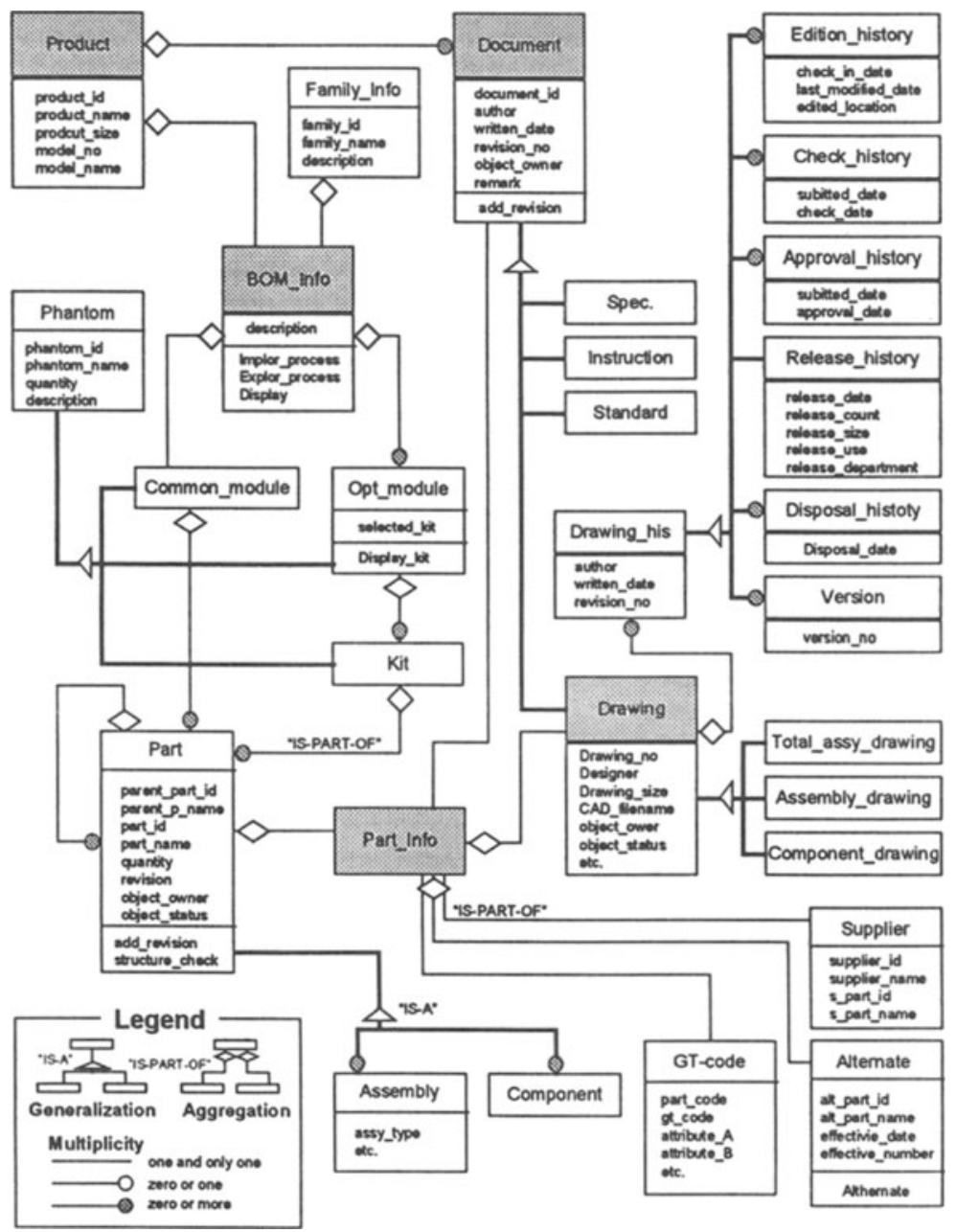

Figure 7. Object model for PDM

\subsection{Dynamic Modeling for Drawings}

Dynamic modeling is to define object states which change according to activities of the object, and to analyze the object life-cycle on how state transition flows precede as time goes by or events break out.

These flows are closely related to the workflow, a set of activities performed by specific events of parts, drawings, documents, etc. As an example, a state transition diagram for drawings is shown in Figure 8. The drawings can be divided into four 
states of on-progress, approval, release, and disposal. The on-progress state is again divided into sub-states of create, check, and edit. A designer creates a new drawing and requests a review to review groups. The reviewers attach their annotations to the drawing. By this time, the drawing keeps the state of onprogress. When an approval is requested, the state of the drawing changes to approval and the decision maker determines approval or rejection. If it is rejected the state of the drawing again changes to on-progress. The printing and release of the drawing is followed by the decision maker's release approval. When he or she determines a disposal, the state changes to disposal.

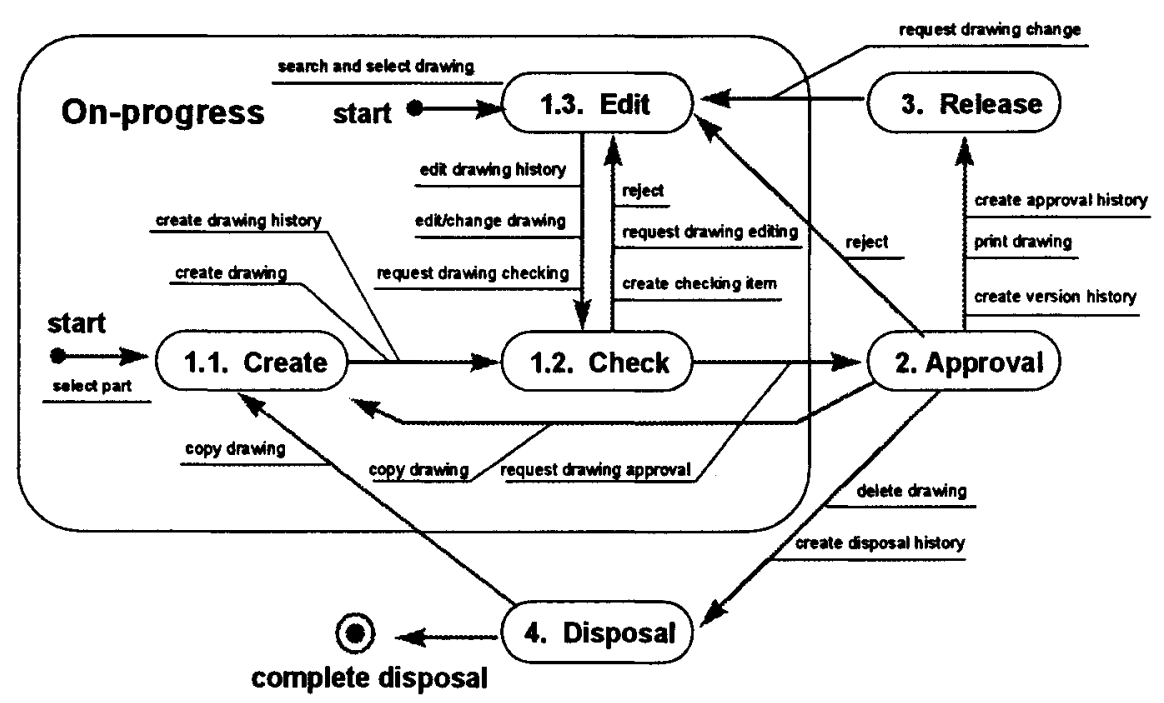

Figure 8. The state transition diagram for drawings

\subsection{Functional Modeling for Drawings and Parts}

The functional model consists of multiple data flow diagrams which specify the meaning of operations and constraints. A data flow diagram (DFD) shows the functional relationships of the values computed by the system, including input values, output values, and internal data stores. The DFD usually contains processes that transform data, data flows that move data, actor objects that produce and consume data, and data store objects that store data passively. The DFDs for drawings and parts are shown in Figures 9 and 10, respectively. In the DFD for drawings, processes for drawings only are included. However, in the DFD for parts, processes for parts, BOM, and GT-codes are all represented. 


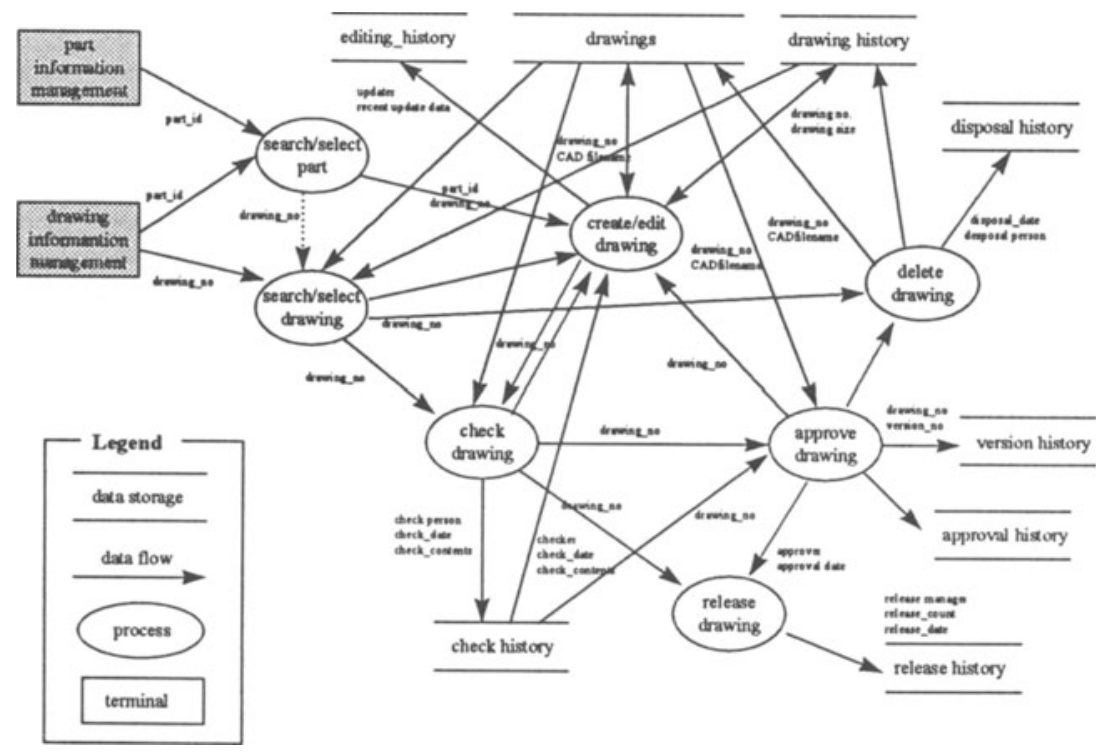

Figure 9. The data flow diagram for drawings

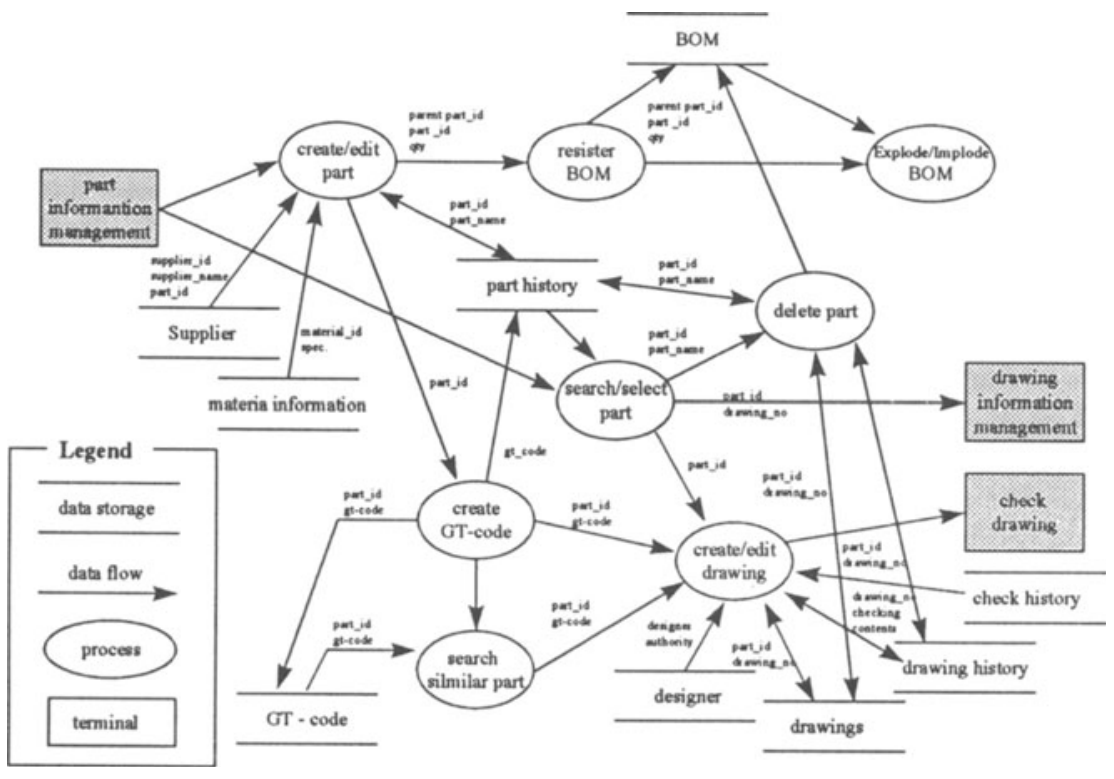

Figure 10. The data flow diagram for parts 


\section{CONCLUSION AND FUTURE RESERCH}

In this research, we have analyzed elements of PDM from the viewpoint of objects and proposed object-oriented models for PDM systems using Rumbough's ObjectModeling Technique (OMT). In the object model for the data share, classes of vaults and workspaces for drawings, parts, documents, etc. have been taken into account. In the object model for the product structure, the concept of a family BOM has been reflected with virtual parts (phantom), options, alternates, etc. In addition, through the analysis of work and data flows for drawings and parts, state transition and data flow diagrams have been proposed. Through the further study for workflow and configuration management modules, we plan to develop an object-oriented prototype for PDM systems.

Acknowledgment: This work was developed with a grant from Korea Research Foundation(01-E-0717).

\section{REFERENCES}

Choi, S.U., Dho, H.S., Kye, W.K., (1996) Trends of Object-Oriented Software Development Methodology, Journal of Information Science, Vol.14, No. 10., 411.

Choi, Y.H., (1995) The PDM System for CE Implementation, December, Computer World, 162-167.

Choi, Y.K., Huh, K.B., (1995) Object-Oriented Software Engineering, Korea Silicon.

Chung, Y., Fischer, G.W., (1994) A Concept and Issues for an Object-Oriented Bill of Materials(BOM) Data Model, Computers \& Industrial Engineering, Vol.26, No.2, 321-339.

CIMdata, (1994) Product Data Management : A Technology Guide.

CIMLINK, (1991) Linkage-Automated Manufacturing Information Flow, CIMLINK.

HP, (1993) Product Data Management : Understanding the Fundamental Technology and Business Concepts, Hewlett-Packard Co.

Kim, C.H., Lim C.K., Chung, W.Y., Kim, W.S., (1994) A Study on the Structure of the EDB System for Engineering Data Integration, Interfaces : Industrial Engineering, Vol.7, No.3, 137-145.

Kim, K.S., Kim, C.H., (1992) A Modeling Methodology for Manufacturing Information Systems based on Object-Oriented Approach, Proceedings of the '92 Conference, KIIE, 192-201.

Kim, S.H., Yoon, H.C., (1994) The Development of the Drawing Information Management System for Technical Document Management, Interfaces : Industrial Engineering, Vol.7, No.3, 213-225. 
Kim, S.H., Shin, Y.H., Moon, H.S., (1996) The Development of the CE-Based Drawing Information Management System, Interfaces : Industrial Engineering, Vol.9, No.1, 41-52.

Kim, W., (1990) Introduction to Object-Oriented Databases, MIT Press.

Lee, C.H., (1996) A Case Study on the Development of the R\&D Integration System Using CALS/PDM. IE Magazine, Vol.3, No.1, 58-62.

Lee, C.H., et al. (1996) The Development of K-CE for Product Development Process Improvement, Interfaces : Industrial Engineering, Vol.8, No.3, 25-37.

McHenry, S., (1993) RDBMS vs. ODBMS for Product Information Management Systems, Proceedings of AUTOFACT' 93 Conference, 28/13-30.

Rumbaugh, J., Blaha, M., Premerlani, W., Eddy, F., Lorensen, W., (1991) ObjectOriented Modeling and Design, Prentice-Hall International, Inc.

Samsung HP, (1993) Implementation Guides for CIM(1,II), Computer Reengineering, Inc.

Shin, Y.K., et al. (1995) An Efficient Structure of the Integration Solution for Technical Information Management, Interfaces : Industrial Engineering, Vol.8, No.3, 197-203.

Taylor, D.A., (1990) Object-Oriented Technology : A Manager's Guide, AddisonWesley Publishing Co.

Yoo, S.B., Seo, H.Y., Ko, K.W., (1995) Product Data Exchange in Production Systems by Use of STEP, Interfaces : Industrial Engineering, Vol.8, No.3, 7595. 